\title{
Multiple Esophageal Ulcerations Caused by a Granular Formulation of Aspirin
}

Pill-induced esophageal injury has been reported with increasing frequency since its initial description in 1970 (1,2). Esophageal injury has been associated with 26 different types of medication (3). Despite its frequent use, aspirin rarely induces pill-esophagitis (4). This type of drug effect has been reported only for the ingestion of tablets or capsules, but never for granularly formulated drugs. We report here two cases of multiple esophageal ulcerations which occurred suddenly in two young men CF and RG, 28 and 18 years old, respectively, after they had taken a granular formulation of aspirin $(600 \mathrm{mg})$ at bedtime for a cold. The two patients underwent esophagogastroduodenoscopy within one and two days of the onset of odynophagia, dysphagia, and retrosternal chest pain (CF), or only retrosternal chest pain (RG). Endoscopy revealed multiple ulcers (eight in CF and six in $\mathrm{RG})(0.3-0.6 \mathrm{~cm}$ in diameter) in the middle and lower esophagus, with no distal esophagitis or hiatal

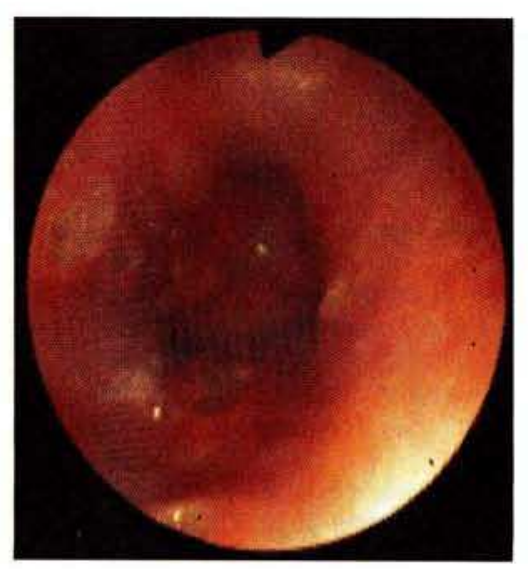

Figure 1:

Endoscopy reveals multiplesuperficial ulcers in the mid-esophagus (CF). The mucosa adjacent to the ulcers appears normal, and there is no evidence of distal esophagitis or hiatal hernia. 
hernia. The ulcers were well marked, and the mucosa adjacent to the ulcers and throughout the rest of the esophagus was normal. Biopsy revealed no evidence of fungi, viral inclusions, or neoplasms. The two patients were instructed to take a standard therapy for esophagitis (omeprazole $40 \mathrm{mg} /$ daily and cisapride $10 \mathrm{mg}$ t.i.d.) for two weeks. Repeat endoscopy after two weeks showed no alterations in either patient. Esophageal manometry carried out one month after the acute episode showed normal peristalsis with a normotensive lower esophageal sphincter. A 24-hour esophageal $\mathrm{pH}$ monitoring was normal in both patients.

S. Rodinó, N. Saccá, A. De Medici, A. Giglio

Servizio di Endoscopia Digestiva, Ospedale G. Ciaccio

Viale Pio X, Catanzaro, Italy

\section{References}

1 Pemberton J: Oesophageal obstruction and ulceration caused by oral potassium therapy. Br. Heart J. 1970; 32: 267-268.

2 Juncosa $L$ : Ulcus peptico yatrogeno del esofago. Rev. Esp. Enferm. Apar. Dig. 1970; 30: 457-458.

3 Kikendall JW, Friedman AC, Oyewole MA, et al.: Pill-induced in jury. Dig. Dis. Sci. 1983; 29: 174-182.

4 Schreiber JB, Covington JA: Aspirin-induced esophageal hemorrhage. J. Am. Med. Assoc. 1988; 259: 1647-1648.

\section{Corresponding Author}

S. Rodinó, M.D.

Via A. Broussard 13, 88100 Catanzaro, Italy 